\title{
Decir lo normal \\ Reflexiones en torno al trasfondo ético del lenguaje de la psiquiatría
}

\author{
Rodrigo Maruy van den Broek \\ Pontificia Universidad Católica del Perú \\ Universidad Antonio Ruiz de Montoya
}

Resumen: Este texto se propone repensar las dimensiones éticas del diagnóstico psiquiátrico en tanto acto de habla. Para ello, exploraremos las tensiones internas al lenguaje de la psiquiatría desde la distinción kantiana entre juicios determinantes y reflexionantes. Luego, enfatizaremos la dimensión performativa del diagnóstico desde Austin y Wittgenstein, problematizando la idea de que este es una descripción objetiva de la anormalidad del paciente. Por último, en diálogo con el enfoque de la injusticia epistémica, propondremos una noción compromisoria de diagnóstico que pueda desempeñarse como un medio de crítica social.

Palabras clave: diagnóstico, psiquiatría, acto de habla, injusticia epistémica, crítica social

\begin{abstract}
This article aims to rethink the ethical dimensions of the psychiatric diagnosis as a speech act. Thereupon, we will explore the internal tensions of the psychiatric language in light of Kant's distinction between determining and reflective judgements. Then, we shall emphasize the performative dimension of the diagnosis from the perspectives of Austin and Wittgenstein, thus problematizing the idea that it is an objective description of the patient's abnormality. Finally, in dialogue with the epistemic injustice approach, we will propose a commissive notion of diagnosis that can also serve as a means for social criticism.
\end{abstract}

Keywords: diagnosis, psychiatry, speech act, epistemic injustice, social criticism 
In philosophizing, I have to bring my own language and life into imagination. What I require is a convening of my culture's criteria, in order to confront them with my words and life as I pursue them and as I may imagine them; and at the same time to confront my words and life as I pursue them with the life my culture's words may imagine for me: to confront the culture with itself, along the lines in which it meets in me. This seems to me a task that warrants the name of philosophy.

Stanley Cavell 1979/1999, 125

\section{§1. Introducción: El lenguaje psiquiátrico y sus tensiones internas}

As I left the ward, I asked one of the psychiatric nurses how Andrew had settled in, hoping to glean some evidence-any evidence- of the kind of psychotic and irrational behaviour that might justify what was being done to him. 'He's excessively polite,' the nurse explained darkly. I raised an eyebrow. 'Can you be excessively polite?' I asked. (...) 'Well', she said, 'we're trying to work out whether his politeness is part of his normal personality or his illness'.

Richard P. Bentall 2010, 111-112

Desde sus orígenes en la Modernidad y en tanto disciplina con pretensiones de legitimidad científica, la psiquiatría ha constituido un saber, cuanto menos, controversial. Bastaría quizás recordar los diversos episodios de reclusiones injustificadas que, a lo largo de los últimos siglos, han generado casos de abuso y de sufrimiento innecesario; recordar quizás la increíble autoridad que otrora ostentaban 'tratamientos' como la terapia electroconvulsiva, el coma insulínico o la lobotomía cerebral. Sin ir demasiado lejos, tales excesos propios de la tradición psiquiátrica han sido magníficamente retratados en la película One Flew Over the Cuckoo's Nest (1975). El argumento es no poco conocido: Randle McMurphy logra evitar volver a ir a la cárcel por sus presuntos crímenes al fingir ser un paciente psiquiátrico; por desgracia, consigue aquello que creía desear y es enviado, más bien, a un manicomio, donde su liberación no dependerá de una condena prefijada por la ley, sino del juicio de los psiquiatras de turno y, en particular, de la tiránica enferma Ratched, a quien nuestro protagonista habrá de estrangular durante unos momentos luego de que esta, inclemente, suscitara mediante amenazas despiadadas que otro recluso, Billy Bibbit, se suicide. Hacia el final 
del relato, Randle es sometido a la 'terapia' de lobotomía, convirtiéndose así en una suerte de entidad vegetal que, sin duda, no provocaría ya mayores disturbios sociales.

En efecto, la historia del poder psiquiátrico está manchada por la sangre indeleble de una brutalidad 'legítima', la cual hoy en día se camufla no en el paradigma carcelario de la reclusión, sino acaso mediante el incremento progresivo y sumamente rentable en la ingesta cotidiana de fármacos para subsanar nuestra falta de adaptabilidad a las incesantes exigencias del sistema. Y sin embargo, nadie en su sano juicio podría negar que la psiquiatría constituye, igualmente, una práctica clínica ejercida por muchas personas que, a la manera de un médico, apuntan en principio a la realización del bienestar individual e, incluso, del bien común'. ¿Cómo conciliar entonces dichos valores laudables con la cruda realidad de las instituciones que han pretendido, sin demasiado éxito, realizarlos? Quizás una entrada particularmente esclarecedora consista en observar su lenguaje, prestando especial atención no tanto al debate ontológico sobre cómo definir la esencia de la salud y de las 'enfermedades mentales', ni a las confrontaciones epistémicas acerca de qué condiciones de verdad y qué clase de evidencia justifican clasificar a alguien como 'normal' o 'patológico'². En cambio, pareciera más

1 Es importante admitir que esta distinción clave entre la psiquiatría como disciplina histórica y los psiquiatras como seres humanos preocupados por la salud de sus pacientes proviene en realidad de Bentall y su prefacio titulado Rational Antipsychiatry (Bentall 2010, xiv-xvi). Asimismo, para cierta evidencia empírica a favor de una "epidemia [contemporánea] de la enfermedad mental" y, sobre todo, de la depresión; o para referencias al curioso hecho de que los pacientes psiquiátricos provenientes de países en vías de desarrollo tienden a tener mejores prospectos de sanación que aquellos en países desarrollados, cf. igualmente Bentall 2010, 17-21.

2 A manera de contextualización, es sabido que el paradigma vigente de la psiquiatría moderna se remite, por su parte, a la 'medicina basada en evidencias', de donde deriva el controvertido 'modelo médico de la enfermedad mental'. En pocas palabras, este modelo postula que las 'enfermedades mentales' se deben fundamentalmente a desbalances químicos de carácter hereditario en los cerebros de los pacientes. Históricamente, es curioso notar que Foucault identifica en cierto sentido el nacimiento de esta concepción de la medicina basada en evidencias con el método anatomoclínico y, en concreto, con las obras de Bichat y de Broussais, quienes entre los siglos XVIII y XIX dejan de comprender a las enfermedades como castigos divinos, como desequilibrios en los humores corporales, o mediante la apelación a cualquier otra entidad ontológicamente dudosa; por el contrario, con la formulación de lo que Foucault denomina como el axioma de la localización y el principio de visibilidad, la enfermedad pasará a tener, necesariamente, una sede (siège) corporal constatable: de este modo, "la medicina se desprende de la metafísica del mal con la cual, desde hace siglos, estaba emparentada; y ella encuentra en la visibilidad de la muerte la forma plena donde su contenido aparece en 
provechoso constatar la manera ordinaria en que dichas categorías, antes bien, son empleadas. Así pues, ¿en qué sentido se efectúan las atribuciones de normalidad o de enfermedad mental?, ¿qué significa, en términos de nuestra comprensión del otro, decir y diagnosticar que alguien padece de depresión, esquizofrenia o de personalidad limítrofe?, ¿qué trasfondo y qué implicancias éticas hay de por medio?, ¿y por qué sería todo esto filosófica, social o incluso políticamente relevante?

Frente a tales preguntas, el propósito de este texto consistirá en repensar las dimensiones éticas del diagnóstico psiquiátrico en tanto acto de habla. En primer lugar, exploraremos las tensiones internas del lenguaje de la psiquiatría y sus pretensiones científicas desde la distinción kantiana entre juicios determinantes y juicios reflexionantes. Acto seguido, enfatizaremos

términos positivos" (Foucault 2015, 880, 888). Luego, hacia finales del siglo XIX, Emil Kraepelin trasladará dicho modelo de corte biológico a la práctica psiquiátrica, incorporando además el énfasis en tratamientos psicofarmacológicos y en la necesidad de clasificar las 'enfermedades mentales' (Bentall 2010, 28-31). Por último, hacia finales del siglo XX, Robert Spitzer y la Asociación estadounidense de psiquiatría (APA), siguiendo las intuiciones centrales de Kraepelin, publicarán la tercera edición del Manual diagnóstico y estadístico de los trastornos mentales (DSM-III) y, en conjunto con los escritos de Gerald Klerman y el desarrollo de las neurociencias y la psicofarmacología, terminará de consolidarse el modelo médico de la 'enfermedad mental' en su versión contemporánea (Bentall 2010, 79-80). Como es bien sabido, uno de los aspectos más criticados de este modelo es la poca importancia que se le confiere a comprensión de las narrativas de los pacientes, así como a aproximaciones de psicoterapia que enfaticen el diálogo y el establecimiento de vínculos interpersonales (Bentall 2010, 80). Así pues, para una discusión crítica acerca de la predominancia del modelo médico de la enfermedad mental en la práctica psiquiátrica y, sobre todo, en el DSM-5, cf. Demazeux: "Quizás el hecho de que [el progreso de] el DSM se ha mantenido sin éxito hasta ahora no es el resultado de una limitación metodológica, sino que puede depender del modelo general que el DSM ha adoptado a partir de la década de 1980: el modelo médico de la enfermedad [illness] mental. Muchas categorías listadas en el DSM pueden no ser verdaderas enfermedades [diseases] después de todo. Esta afirmación escéptica no involucra necesariamente ninguna posición anti-psiquiátrica; solo nos recuerda que la pregunta "¿qué es un trastorno/enfermedad mental?" nunca ha alcanzado una solución consensuada, y continúa dividiendo a filósofos y clínicos" $(2015,21)$. Todas las traducciones del inglés y del francés son propias. Ahora bien, valdría la pena matizar que dentro de las 'enfermedades mentales' hay distinciones importantes: por ejemplo, hay muy poca controversia acerca de que gran parte de los trastornos del lenguaje se remiten a lesiones cerebrales en el área de Broca; por otro lado, casos de esquizofrenia, desorden bipolar o depresión endógena también manifiestas alteraciones patentes en el funcionamiento del cerebro, pero ahí surge el debate en torno al problema causa-efecto: ¿son las alteraciones cerebrales la causa o la consecuencia de los problemas sociales que rodean al paciente? Por último, los trastornos de la personalidad constituyen algunos de los casos más controversiales, ya que ni siquiera es patente una alteración constatable en el funcionamiento del cerebro. Piénsese, sin ir demasiado lejos, en que la homosexualidad era considerada como una 'enfermedad mental' hace no más de 50 años. Para un análisis detallado, cf. directamente el DSM-5 (2013). 
la dimensión performativa del diagnóstico desde las reflexiones de Austin y de Wittgenstein en torno al lenguaje. En concreto, se mostrará que, lejos de ser la descripción objetiva de una condición psíquica o biológica de anormalidad, el diagnóstico es ante todo un acto de habla y, como tal, vehicula una transformación en el estatuto socio-ontológico del paciente; transformación que ha tendido a expresarse de modo judicativo y, lamentablemente, en consonancia con los abusos de poder propios de la tradición psiquiátrica. Por lo tanto, a manera de conclusión y en diálogo con el enfoque de la injusticia epistémica desarrollado por Miranda Fricker y José Medina, propondremos en cambio una noción compromisoria de diagnóstico que pueda desempeñarse políticamente como un medio de crítica social y, asimismo, como un modo de enfrentarse a la creciente tendencia a privatizar malestares anímicos.

Con la finalidad de abordar nuestro primer objetivo, partamos de un caso concreto. El célebre Curso de psiquiatría de Honorio Delgado sugiere que "en principio, el criterio de anormalidad en psicopatología debe ser puramente descriptivo, en el sentido de que no entrañe una valoración de inferioridad personal, ni de enfermedad, falta de libertad, sufrimiento, etc." (Delgado 1993, 15; cursivas añadidas). En otras palabras, se diría que clasificar a alguien como'anormal'es en el fondo la descripción objetiva de un hecho del mundo, el cual ha de remitirse a dos criterios de justificación. Por un lado, el criterio estadístico, a pesar de no ser absoluto, implica la ausencia de un juicio de valor y puede establecerse científicamente en función a la frecuencia (Delgado 1993, 16). En cambio, el criterio teleológico respondería más bien a la esencia funcional del organismo o a su tipo ideal cualitativo (Delgado $1993,16)$. Con todo, es preciso enfatizar que el autor es lo suficientemente cauto para reconocer que se trata de criterios complementarios, y cuya aplicación depende en última instancia de la experiencia y del juicio del psicopatólogo para evaluar cada caso particular (Delgado 1993, 17). Hay, por ende, una tensión interna entre la búsqueda de una descripción puramente científica y la necesidad de recurrir al discernimiento, a la intuición 
y a la facultad de juzgar para poder denominar a alguien como normal o anormal ${ }^{3}$.

Ahora bien, no se trata de un caso aislado. El mismísimo Manual diagnóstico y estadístico de los trastornos mentales (DSM-5) de la Asociación estadounidense de psiquiatría (APA) incurre en las mismas tensiones. En primer lugar, se afirma que "los criterios son concisos y explícitos y pretenden facilitar una evaluación objetiva [objective assessment] de las presentaciones de los síntomas en una variedad de escenarios clínicos" (APA 2013, xli; cursivas añadidas). Por otro lado, no tarda en acotarse que el DSM constituye en realidad un "esquema cognitivo históricamente determinado", donde ciertos factores "no están sujetos a designaciones categóricas estrictas", ya que "los trastornos mentales se definen en relación a normas y valores culturales, sociales y familiares" (APA 2013, 10, 14). Así, la conclusión parece caer por su propio peso: "El juicio de que un comportamiento dado es anormal y requiere atención clínica depende de normas culturales que son internalizadas por los individuos y aplicadas por otros alrededor de ellos, incluyendo miembros de familia y clínicos" (APA 2013, 14). Ello quiere decir que es imposible pensar la atribución de una 'enfermedad mental' en abstracto o bajo un modelo mecánico de clasificación universal que subsuma todos los casos particulares; es necesario, en cambio, considerar la totalidad de las circunstancias comunicativas de atribución e, incluso, partir siempre de

3 A este respecto, es sabido que Kant, en su Crítica de la facultad de juzgar, elabora una distinción de suma importancia: por un lado, la facultad de juzgar es determinante (bestimmend) cuando esta subsume un caso particular bajo el principio o la regla universal dada; en cambio, esta es reflexionante (reflektierend) cuando parte de un particular dado para descubrir un universal posible (Kant, 1985, V 179-184, 105-111). No obstante, es indispensable enfatizar este punto: Kant no está ofreciendo una tipología de los juicios (Urteile) a la manera de la Crítica de la razón pura (1787), sino ante todo una caracterización de las dos formas en que opera la facultad de juzgar (Urteilskraft): la forma determinante es aplicativa; la forma reflexionante, creativa. Ambas dinámicas son complementarias y, de hecho, no sería difícil reconocer que el problema del diagnóstico de una patología, sobre todo mental, precisa de dicha complementariedad: es a partir de la forma reflexionante que se llega a acuñar nuevos conceptos de clasificación; es mediante el ejercicio determinante que uno denomina a un individuo concreto como padeciendo tal o cual trastorno. De momento, bastará indicar que estas reflexiones sobre el juicio serán retomadas hacia el final del presente texto. Por otro lado, para una propuesta bastante sugerente sobre cómo - desde la interpretación política que Hannah Arendt (1977) ofrece de la Crítica de la facultad de juzgar-es posible pensar éticamente el juicio reflexionante a partir de la narratividad, cf. la obra de María Pía Lara: Narrar el mal. Una teoría postmetafísica del juicio reflexionante (2009). 
los padecimientos concretos del individuo de carne y hueso que precisa de ayuda psiquiátrica ${ }^{4}$.

¿Cómo entender entonces el acontecimiento social del diagnóstico? En efecto, ¿qué ocurre exactamente cuando el psiquiatra enuncia que un sujeto padece tal o cual condición patológica o, por el contrario, que es 'completamente' normal? Sin lugar a dudas, el mismo lenguaje de la psiquiatría está dispuesto a conceder que no se trata de una mera constatación fáctica sub specie aeternitatis, pero quizás habría aún reticencias comprensibles en abandonar la creencia de que aquella 'descripción pura' es, en cierto sentido, el ideal asintótico hacia el cual la disciplina en cuestión ha de tender. No es de extrañarnos. Después de todo, al igual que en el caso de ciertas ramas de la filosofía, la tradición psiquiátrica ha pretendido desde sus orígenes alcanzar el estatuto de 'ciencia estricta': tampoco es casual que, como bien sugiere Bentall, el mismo Emil Kraepelin, considerado el padre de la psiquiatría moderna por sus contribuciones en el abordaje biológico y genético de las 'enfermedades mentales', "tomara inspiración de las obras de su hermano mayor Karl, un distinguido botánico muy conocido por sus investigaciones en la clasificación de especies vegetales" (Bentall $2010,110-111)^{5}$. Ahora bien, para poder abordar ética y filosóficamente el acontecimiento social del diagnóstico desde su enunciación, será indispensable tematizar qué concepciones o, mejor aún, qué usos del lenguaje se encuentran en juego en dichas circunstancias comunicativas.

4 Vale la pena notar que Canguilhem rescata la obra de Jaspers como una propuesta de cambio de perspectiva fundamental en la tradición psiquiátrica: lejos de someterse al canon de la autoridad incuestionable del juicio del experto, Jaspers apuesta por un giro fenomenológico: “Es la apreciación del paciente y las ideas dominantes del entorno social más que el juicio del médico lo que determina aquello que llamamos 'enfermedad"' (Jaspers citado por Canguilhem 1966/2015, 97). De ahí que su magnum opus, Psicopatología general (1913), incorpore un sinnúmero de testimonios de pacientes, los cuales apuntan no a una teoría explicativa de las enfermedades mentales, sino a una visión comprensiva de los distintos matices y escorzos del sufrimiento individual, así como de sus expresiones narrativas.

5 Para una descripción histórica bastante sugerente acerca del vínculo epistemológico entre la psicopatología y la botánica, cf. el célebre capítulo de Historia de la locura en la época clásica (1961) que, no sin astucia, Foucault titula como « Le fou au jardin des espèces». 


\section{§2. El lenguaje como acción: repensar el trasfondo ético del diagnóstico}

And if I say "They are crazy" or "incomprehensible" then that is not a fact but my fate for them. I have gone as far as my imagination, magnanimity, or anxiety will allow; or as my honor, or my standing cares and commitments, can accomodate.

Stanley Cavell, 1979/1999, p. 118

En la sección anterior, se ha expuesto una serie de razones por las cuales la tradición psiquiátrica se encontraría, en principio, comprometida con el ideal de una concepción descriptiva e imparcial del lenguaje que, a partir de una teoría explicativa de la enfermedad mental, pueda emitir juicios determinantes acerca de la condición, normal o patológica, de los individuos de carne y hueso. No obstante, también se ha hecho énfasis en los riesgos de abuso y maltrato que aquel modelo aplicativo del diagnóstico puede traer a colación: por ejemplo, reducir o condenar a las personas a una condición, categoría o estereotipo estricto que, además, es en muchos casos considerado como 'incurable'6. No en vano existen psiquiatras $y$, sin lugar a duda, psicólogos que optan más bien por abordar el malestar específico de sus pacientes desde un enfoque comprensivo que, a partir de su facultad reflexionante de juzgar, priorice el establecimiento de relaciones humanas comunicativas, antes que el mero recurso paradigmático a la medicación. ¿En qué sentido una filosofía del lenguaje ordinario podría arrojar luces sobre esta disputa en el seno de la psicopatología?

6 A propósito del tópico de la estigmatización social, es muy interesante la manera en que Bentall critica las implicancias de adoptar, no sin convicción, un modelo genético y biológico de la enfermedad mental: "si las personas ordinarias creen que los desórdenes psiquiátricos son enfermedades [illnesses] que no son diferentes a otros tipos de enfermedad, así reza el argumento [tradicional], entonces los pacientes psiquiátricos serán aceptados en vez de ser rechazados"; por desgracia, el hecho de asumir que el comportamiento 'anormal' de una persona no responde a sus circunstancias actuales ni a su historia de vida, sino a un defecto congénito e inmodificable ha fomentado más bien que, en la realidad, la discriminación aumente en lugar de reducirse (Bentall 2010, 120). Pareciera obvio: si el comportamiento errático de un amigo o familiar es visto, caritativamente, como una reacción comprensible y potencialmente pasajera ante ciertos acontecimientos desafortunados, tiene sentido: es plausible la empatía e, incluso, el apostar por la sanación del otro, guardando siempre proximidad y cuidado (soin, care, Sorge); en cambio, si aquella esperanza de cura es arrojada en principio por la ventana, entonces la distancia tenderá a disfrazarse, fría, de único remedio posible. Lo normal, como bien argumentaremos, es también un asunto de comprensión y de "los límites" de la comprensión. 
Antes que nada, cabría señalar que, como bien indica Wittgenstein a lo largo de sus Investigaciones filosóficas, tal aproximación ordinaria al lenguaje se opone a una noción abstracta del significado, según la cual el sentido de las palabras consistiría primordialmente en describir la realidad a través de una relación de correspondencia con determinados objetos o hechos: en contraste con las pretensiones totalizantes de esta concepción 'ostensiva' del lenguaje $y$, asimismo, cuidándose de no incurrir en enunciados universalistas, Wittgenstein sugiere más bien que, en muchos casos, "el significado de una palabra es su uso [Gebrauch] en el lenguaje" (Wittgenstein 1953/2002, $\S 43,60-61)$. ¿Qué se quiere decir mediante semejante afirmación? Justamente que, para significar, las palabras no necesitan referirse a una esencia semántica invariable almacenada en las mentes de los hablantes (o en el orden platónico de las ideas); por el contrario, la significación cobra sentido en y desde la práctica comunicativa, es decir, en relación con determinadas exigencias, expectativas, normas, valores y, en general, reglas cuyo carácter es fundamentalmente público y social. No existe, pues, una teoría explicativa del significado, sino que resulta más conveniente pensar en las definiciones ostensivas como un "juego del lenguaje" entre muchos otros que, evidentemente, estaría sujeto al cambio, a la temporalidad y, en última instancia, a las motivaciones pragmáticas propias de toda enunciación. Un juego del lenguaje que, por cierto, no se encuentra libre de riesgos ni de problemas para el caso de la psiquiatría tradicional.

Ahora bien, dichas reflexiones sobre los límites y los compromisos prácticos del significado nos obligan a explicitar aquello que ya había sido sugerido incluso desde el mismo lenguaje de la psiquiatría, a saber: que no existe una teoría abstracta, omnicomprensiva ni explicativa de la normalidad. Y sin embargo, el problema pareciera perfilarse de manera bastante más profunda: en primer lugar, si bien no existe una tal teoría, ¿qué ha de impedir que la tradición psiquiátrica siga tomándola como parámetro científico y normativo? Es decir, ¿qué habría de malo o de terrible en apuntar asintóticamente a una descripción pura de la normalidad o, si no, a perfeccionar aquel juego ostensivo del lenguaje? A este respecto, no es fortuito que Cavell, con increíble perspicacia, nos recuerde que "si existe semejante teoría [de la normalidad], dicha teoría radica en los criterios mismos o, para decirlo de otro modo, los criterios son los que cualquier teoría tendría que explicar 
(...) la normalidad es una cuestión práctica; o una cuestión de los límites de la práctica" (Cavell 1979/1999, 90). Volvamos entonces brevemente a los dos criterios propuestos por Honorio Delgado: el estadístico y el teleológico.

Para replantear este problema, un interlocutor decisivo será Georges Canguilhem y su obra Lo normal y lo patológico. Desde una perspectiva médica de la enfermedad, es decir, sin incurrir en los problemas epistémicos u ontológicos propios de la psicopatología, Canguilhem compara el concepto de normal con aquel de anómalo. Desde esta óptica, la anomalía no representa sino una mera diferencia (écart) respecto del tipo común, estadístico; mientras que la anormalidad sería propiamente aquella diferencia que resulta nociva para el organismo; en cambio, lo normal habrá de corresponder respectivamente con lo normativo, es decir, con aquella capacidad del ser viviente para instituir normas vitales (Canguilhem 1966/2015, 120). Ahora bien, la genialidad de Canguilhem consiste en pensar la diferencia entre anómalo y anormal no a partir del organismo per se, sino de la relación (rapport) que este establece con el entorno (milieu): “El ser viviente y el entorno no son normales tomados de forma separada, sino que es su relación la que los hace tales a uno y al otro" (Canguilhem 1966/2015, 120). Ello significa que una anomalía solo puede ser considerada como anormal en relación con un cierto entorno en el cual se revela como desfavorable, mientras que en otros contextos podría fácilmente imponerse como un atributo normativo. Como de costumbre, pero sin el tedio de lo habitual, el cine proporciona un 'testimonio estético' reciente que permitirá ilustrar estas sutilezas conceptuales.

En un escenario no inverosímil donde la atmósfera de la Tierra se vuelve finalmente tóxica, Sam Walden es una de las pocas personas que, en lugar de abandonar el planeta para vivir como la mayoría de sobrevivientes en una estación espacial cerca de Júpiter, decide más bien continuar la heroica pero acaso cándida y fútil tentativa de su padre, difunto, por limpiar el aire terrestre a través de abejas y plantas que se hayan vuelto inmunes a la toxicidad del entorno. Pronto aparecerá Micah, otro sobreviviente de la catástrofe que, en parte, había perdido a su familia debido a las falsas esperanzas que el padre de Sam pregonaba. Su intención era, de una vez por todas, asesinarlo; pero ante la noticia de que el tiempo y la atmósfera 
habían cumplido ya esa tarea, Micah decide más bien salvar a Sam del destino que su padre le había impuesto. Una última nave, por desgracia lejana, partiría pronto. No queda mucho tiempo y el rescate se trastoca entonces en una mezcla apocalíptica entre romance, deseo y responsabilidad de salvar a la especie: hacen el amor. Luego, hacia el clímax de la narrativa y frente al magnífico cuadro Leda au cygne de Cézanne (1880), el cual se preservaba todavía en un museo derruido, Sam Walden decide sacarse el casco de oxígeno que la protegía del entorno y arriesgar, ante la inminencia del escape, su última esperanza. Vive. Sus pulmones se habían adaptado a la toxicidad y, a manera acaso de un deus ex machina, nueve meses después daría a luz a un hijo, inmune también, fruto de la relación que tuvo con Micah. La tierra puede empezar a repoblarse.

Tal es, grosso modo, la ilustración que la película lo (2019) ofrece del problema de la normalidad: los pulmones de Sam Walden desarrollaron una anomalía que, no obstante, era normativa respecto del entorno; habían logrado adaptarse, imponerse, prevalecer. Quizás en una atmósfera limpia aquellos mismos pulmones se sofocarían en segundos, quizás, pero no en aquel escenario: en aquel escenario, los pulmones comunes eran anormales. ¿Y qué ocurre entonces? Lo anormal perece y lo normativo se reproduce, y la reproducción se convierte así en frecuencia estadística. En palabras de Canguilhem, lo normal no se deriva de la media (moyenne), sino que se traduce en la media: más aún, "en la especie humana, la frecuencia estadística no traduce solamente una normatividad vital, sino una normatividad social. Un rasgo humano no sería normal porque frecuente, sino frecuente porque normal, es decir, normativo (...)" (Canguilhem 1966/2015, 135). Por lo tanto, el criterio estadístico se muestra como el reflejo contingente de un criterio más profundo de normatividad, anclado en una relación dinámica de adaptación con el entorno y, en nuestro caso, con las costumbres.

7 A propósito de la perspectiva tradicional de 'los psiquiatras', Canguilhem es sumamente agudo al sostener que "[ellos conciben lo normal como] una cierta forma de adaptación a lo real o a la vida que, a pesar de todo ello, no tiene nada de absoluto, excepto para quien jamás ha sospechado la relatividad de los valores técnicos, económicos o culturales, para quien adhiere sin reserva al valor de estos valores y que, finalmente, olvidando las modalidades de su propio condicionamiento por su entorno y la historia de este entorno, y pensando demasiado ingenuamente que la norma de las normas se encarna en él, se revela ante cualquier pensamiento mínimamente crítico como víctima de una ilusión bastante cercana de aquella 
Del mismo modo, la noción evolutiva de anomalía pone en tela de juicio cualquier pretensión teleológica por encontrar una esencia funcional del organismo o un tipo ideal fijo, los cuales se encontrarían exentos de los vaivenes del devenir. En pocas palabras, no solamente no hay, sino que tampoco puede haber una teoría explicativa provista de criterios claros y distintos que abarquen todos los casos posibles de anormalidad. Por lo tanto, el concepto de normal no es en absoluto descriptivo, ni siquiera en términos biológicos, sino fundamentalmente normativo y por ende objeto de discusión filosófica (Canguilhem 1965/2015, 218). El psiquiatra está condenado, pues, a valerse de su juicio para diagnosticar.

Ahora, ello no tendría por qué conducirnos al oxímoron de un relativismo absoluto donde la distinción entre lo normal y lo patológico se desvanezca. Por el contrario, creemos que Cavell tiene razón al indicar que "las diferencias entre normalidad y anormalidad son filosóficamente no tan instructivas como su unidad fundamental - que ambas dependen del mismo hecho de la civilización" (Cavell 1979/1999, 112). En consecuencia, que los criterios de normalidad se encuentren siempre anclados a un contexto preciso y respondan, además, a motivaciones pragmáticas de enunciación los vincula necesariamente con ciertos juegos del lenguaje, ciertas formas de vida, ciertas prácticas sociales y ciertos valores compartidos o, en términos de Hans Joas, ciertos lazos de valor (Wertbindungen) (Joas 2006, 4). En consecuencia, ahí donde se asuma y se hable como si una visión del mundo fuera natural, desinteresada y meramente descriptiva, es necesario sospechar de tales pretensiones de imparcialidad y preguntarse, antes bien: ¿cuáles son los criterios valorativos que se encuentran en juego para determinar lo que es considerado como normal?, ¿qué trasfondo ético yace en el horizonte?, ¿qué compromisos y qué motivaciones pragmáticas orientan a este ser humano de carne y hueso, a este habitante de determinada sociedad y de

que él mismo denuncia en la locura (...) [en cambio] la norma, en materia del psiquismo humano, es la reivindicación y el uso de la libertad como poder de revisión y de institución de las normas, reivindicación que implica normalmente el riesgo de locura" (Canguilhem 1965/2015, $216,217)$. Ahora bien, será en la última sección del presente texto donde se retomen estas reflexiones en torno al potencial crítico de repensar políticamente el diagnóstico en tanto acto de habla. 
determinada época, para denominar a aquella otra persona como mentalmente patológica?

Volvamos sobre el lenguaje y sobre un ejemplo concreto: ¿qué ocurre cuando el Dr. X diagnostica al paciente $\mathrm{Z}$ como un caso de trastorno de personalidad limítrofe? Antes que nada, un enunciado: "Usted padece de trastorno de personalidad limítrofe". El psiquiatra se vale de su facultad determinante de juzgar. Juzga. Y sin embargo, ¿se trata de una descripción? Por todo lo que se ha argumentado hasta ahora: difícilmente. El lenguaje no está funcionando aquí como una manera de representar la realidad, sino que se está imponiendo sobre, está configurando una realidad particular y, además, está permitiendo que el Dr. X se posicione éticamente en relación con el paciente $Z$. Todo diagnóstico es, en última instancia, un compromiso y, acaso, una promesa.

Con la finalidad de comprender mejor las dimensiones de este fenómeno, valdría la pena efectuar un breve excurso para remitirnos a J. L. Austin y, en concreto, a su obra Cómo hacer cosas con palabras. En efecto, nuestro autor tomará como punto de partida el presupuesto occidental, ya denunciado por Wittgenstein, de que la función principal del lenguaje consiste en describir la realidad. A fin de poner en tela de juicio las pretensiones de dicha falacia descriptiva, Austin explorará los casos donde las personas, mediante sus palabras, realizan acciones. En primera instancia, dichos "actos de habla" serán denominados performativos, y habrán de ser contrastados con los enunciados constatativos. Algunos casos cotidianos que dan cuenta de esta dimensión performativa del lenguaje son, por ejemplo, el bautizo de un barco, la declaración de que una pareja está ahora casada o de que una persona ha sido encontrada culpable de un crimen, el pronunciamiento de que un partido de fútbol ha terminado o, como el lector habrá podido intuir, un diagnóstico psiquiátrico.

Es evidente que, en tales ocasiones, los usos lingüísticos no describen realidad alguna, sino que, en función a determinadas convenciones, ejercen una acción concreta en el mundo e incluso modifican la realidad. En este sentido, los performativos no pueden ser, como en el caso de los constatativos, verdaderos ni falsos, sino que han de ser juzgados, antes bien, como 
"felices" o "infelices" en su consecución (Austin 1962, 12-14). Tras enumerar una serie de condiciones necesarias en torno a las convenciones y a la disposición de los agentes para que un performativo sea feliz, Austin se propone encontrar un criterio claro y distinto para diferenciar dicho acto de habla de los meros constatativos: curiosamente, resulta que ni la gramática ni criterios semánticos o proposicionales (in/by) bastarán para efectuar aquella distinción de manera unívoca y concluyente (Austin 1962, 94). De hecho, como bien indica Shoshana Felman, cuando Austin reconoce que existen performativos implícitos, entonces es necesario admitir también que virtualmente cualquier constatativo puede funcionar como un performativo implícito (Felman 2003, 8).

Ante tales 'aporías' metodológicas, Austin decide cambiar de estrategia y reemplazar la distinción entre los performativos y constatativos por una triple caracterización de los enunciados en tanto actos de habla. En otras palabras, el análisis del lenguaje cotidiano revela que decir es siempre, y de manera fundamental, un hacer, de modo que, nuevamente, las cuestiones relativas al significado no pueden ser reducidas a una teoría universal omnicomprensiva ni sometidas a una dicotomía categórica fundada en criterios absolutos de verdad y falsedad. Por el contrario, al preguntarse de manera más precisa qué significa hacer, Austin descubre que los actos de habla remiten a una dimensión locucionaria (el significado de una oración a partir de sus aspectos fonéticos, fáticos y réticos), ilocucionaria (el llevar a cabo, mediante palabras, un acto social en relación a determinadas costumbres y convenciones que le confieren cierta fuerza ejecutiva independiente de la intención del hablante) y perlocucionaria (el efecto prácticamente impredecible generado en el o los distintos interlocutores) (Austin 1962, 94-101). No se trata, dicho sea de paso, de diferencias rígidas y perentorias, sino de meras distinciones analíticas que sirven para enfatizar aspectos de un mismo fenómeno, a saber, el acto de habla.

Desde esta óptica, es necesario considerar que, en tanto hacer, la enunciación constituye un acontecimiento social: por tal motivo, tanto el significado como el valor apofántico de una oración están condicionados e incluso dependen del uso y del contexto ordinario de enunciación. De nuevo, pareciera que Austin coincide con Wittgenstein en que la pragmática constituye 
el trasfondo hermenéutico de la semántica y no es, como se había supuesto tradicionalmente, a la inversa. $\mathrm{O}$, yendo incluso más lejos, se diría que ambas dimensiones son rizomáticamente indisociables, de modo que no es posible comprender una sin la otra y, a fortiori, la distinción entre ambas se torna evanescente. Por último, Austin procederá a distinguir cinco clases o, más precisamente, cinco familias superpuestas de actos de habla: los judicativos (verbigracia, 'estás despedido'), ejercitativos ('te ordeno ir a tu cuarto'), compromisorios ('te juro que lo haré'), comportativos ('agradezco tus palabras') y expositivos ('postulo que la tierra es plana') (Austin 1962, 150). Estas se encontrarán, además, interrelacionadas con las dimensiones locucionarias, ilocucionarias y perlocucionarias patentes en el uso ordinario de los actos de habla.

Vale la pena enfatizar un último punto de este breve excurso: estamos de acuerdo con Nancy Bauer cuando señala que la intención de Austin no consiste en "producir una teoría viable de la competencia lingüística o una descripción de las convenciones y quasi-convenciones que gobiernan la ilocución en el lenguaje natural, sino en llamar nuestra atención respecto de la capacidad humana de hacer varios compromisos a y en presencia de otros" (Bauer 2015, 95). En tal sentido, Cómo hacer cosas con palabras no conforma una empresa teorética, sino una indagación a propósito de "aquello que es exigido de nosotros en tanto seres sociales" cuando establecemos, justificamos, imponemos y evadimos juicios (Bauer 2015, 95). Así pues, es evidente que nuestro uso cotidiano del lenguaje y, en general, nuestra competencia lingüística no posee primordialmente una función representativa o referencial del mundo, sino que muestra las diversas formas de posicionarnos éticamente ante otras personas al momento de hablar (Bauer 2015, 92, 97). La pregunta pareciera entonces caer por su propio peso: en concreto, ¿qué ocurre con el diagnóstico en tanto acto de habla?

Depende. Desde la tradición psiquiátrica más estricta, uno podría pensar que se trata de un mero acto explicativo; pero de nuevo, ello equivaldría a incurrir en el leitmotiv de la falacia descriptiva que ha sido ampliamente criticado por Wittgenstein y Austin. Entonces, quizás sea más sincero admitir que puede tratarse, antes bien, de un acto judicativo: quizás, lo que la fuerza ilocucionaria del diagnóstico hace es, a la manera del veredicto 
de una autoridad jurídica, vehicular una transformación en el estatuto socio-ontológico de la persona concernida. De acuerdo a nuestras convenciones y prácticas vigentes, el acusado se convierte en convicto; el paciente, ¿en un enfermo?, ¿en un anormal? No olvidemos que, como bien indica Constantinidès (2000) a propósito de las motivaciones genealógicas de Nietzsche, "las palabras son en cierto modo sedimentaciones de valores" (Constantinidès 2000, 230). Hay entonces un impacto ético considerable al denominar, clasificar y hasta transformar performativamente a alguien en un 'enfermo' o en un 'anormal'. Por ende, quizás convendría invertir la perspectiva y efectuar otro giro fenomenológico: preguntarnos no qué ocurre con el paciente, sino con el psiquiatra. Al momento de enunciar su diagnóstico, ¿no se está comprometiendo acaso con la sanación del malestar que carga aquel ser humano de carne y hueso, quien comparece ante su autoridad?, ¿no es ese su posicionamiento ético fundamental?

De nuevo: depende. Depende en gran medida de si el Dr. $X$ se ha valido de su 'ojo clínico' y de su facultad determinante de juzgar para realizar un diagnóstico certero e inapelable; o de si, en cambio, ha verdaderamente escuchado y comprendido desde su facultad reflexionante la narrativa que el paciente $Z$, quizás en desesperación, articula para intentar darle un sentido a su sufrimiento. No se trata de un problema superfluo: la narratividad es, después de todo, un aspecto constituyente del ser humano. Tal vez convendría recordar que, no sin razón, Alasdair Maclntyre sentencia que "el hombre, tanto en sus acciones y sus prácticas como en sus ficciones, es esencialmente un animal que cuenta historias [story-telling animal]" (Maclntyre 1981/2007, 216). Así pues, resulta significativo e, incluso, sintomático que, como bien indica Bentall, el "error fundamental de la psiquiatría" haya consistido en proclamar que las 'enfermedades mentales' se ocasionan por condiciones genéticas y biológicas, de modo que resulte mucho más importante enfocarse en tener un diagnóstico adecuado para recetar una medicación efectiva que tomar en serio las historias (stories) de los pacientes (Bentall 2010, 143-144). Más allá de la falta de evidencia empírica disponible en favor de este modelo médico de la enfermedad mental, el 
impacto ético sobre la práctica clínica como una práctica centrada en la escucha y en la comprensión es, cuanto menos, alarmante ${ }^{8}$.

Hoy en día, no pareciera exagerado constatar que el diagnóstico, en tanto acto de habla, deja de (o sigue sin) ser un compromiso ético. Al contrario, se trata sobre todo de una atribución de responsabilidad con pretensiones constatativas. En efecto, sin importar demasiado su historia y sin poseer voz ni voto en lo que concierne a la elaboración conjunta de un tratamiento particular, el paciente promedio tiene que cumplir las órdenes del psiquiatra de turno y ser lo suficientemente responsable para tomar sus medicinas a tiempo: así habrá de recuperar el balance en su química cerebral; así podrá, finalmente, tener una chance de ser normal y, entonces, ser aceptado y engullido por el sistema. Su sanación depende, en última instancia, no de la calidad del vínculo que pueda establecer con su terapeuta, sino de su propia convicción y disciplina. Por supuesto, es difícil constatar en esta aplicación del modelo tradicional del lenguaje psiquiátrico siquiera rastros de un encuentro comunicativo y compromisorio. Por el contrario, acaso haya más honestidad en admitir que, valiéndonos de la propuesta de José Medina y su diálogo con Miranda Fricker, se trata más bien de un escenario de injusticia e incluso de muerte hermenéutica, esto es, un escenario donde se hace patente "la pérdida (o recorte radical) de la propia voz, de las propias capacidades interpretativas, o del propios estatuto como un participante de prácticas que producen y comparten sentido [meaning-making and meaning-sharing practices]" (Medina 2017, 41). ¿No valdría entonces la pena siquiera contemplar la posibilidad de reemplazar el ideal diagnóstico de una 'descripción pura', en cambio, por un ideal del compromiso sincero o, en términos de Austin, feliz?

8 Para una discusión detallada acerca de cómo la tradición psiquiátrica ha malinterpretado y por ende sobrevalorado la importancia de la hereditabilidad $\left(\mathrm{h}^{2}\right)$ en los desórdenes mentales, así como una crítica de la influencia perniciosa de la industria farmacéutica en la fabricación y publicación de data discutible mediante pruebas controladas aleatorizadas, cf. Bentall 2010, 


\section{§3. Conclusión: Pensar políticamente el lenguaje de la psiquiatría}

To think of a human activity as governed throughout by mere conventions, or as having conventions which may as well be changed as not depending upon some individual or other's taste or decision, is to think of a set of conventions as tyrannical. It is worth saying that conventions can be changed because it is essential to a convention that it be in service of some project, and you do not know a priori which set of procedures is better than others for that project. That is, it is internal to a convention that it be open to change in convention, in the convening of those subject to it, in whose behavior it lives. So it is a first order of business of political tyranny to deny the freedom to convene.

Stanley Cavell, 1979/1999, p. 120

En la sección anterior hemos esbozado una serie de razones por las cuales convendría repensar, desde una filosofía del lenguaje ordinario, el rol o, más precisamente, el tipo de acción que constituye el acontecimiento performativo de diagnosticar, así como algunas de sus implicancias éticas. Para ello, se había recurrido a la diferencia entre un modelo judicativo tradicional que partiera de una operación determinante de la facultad de juzgar y consistiese sobre todo en atribuir responsabilidades de ingesta farmacológica, por un lado; y un modelo compromisorio o, en todo caso, hermenéutico que abordara las narrativas de los pacientes desde una operación reflexionante de la facultad de juzgar y, por lo mismo, consistiese en asumir responsabilidades y forjar vínculos significativos. No se trata, por cierto, de una propuesta demasiado novedosa: el mismo Bentall ofrece una caracterización similar al cotejar "dos visiones para el futuro del cuidado psiquiátrico": una paternalista y centrada en el modelo médico de la 'enfermedad mental'; otra que promueve, en cambio, la autonomía testimonial del paciente (Bentall 2010, 268-270). Aun así, convendría rescatar la siguiente acotación: "muchos profesionales de la salud mental se colocarían quizás entre los dos polos indicados por esta tabla, pero eso no quiere decir que las distinciones trazadas aquí no sean reales ni importantes" (Bentall 2010, 268, cursivas añadidas). Acaso habría que decir lo mismo del lenguaje de la psiquiatría.

Así pues, quizás la novedad del presente texto consista en haber pensado dichos modelos desde las implicancias éticas de sus usos lingüísticos y no 
tanto, como usualmente se ha hecho, desde la cantidad de evidencia empírica disponible a favor de una postura o la otra. Quizás, hayamos hecho bien en enfatizar la necesidad de tomar en cuenta y de partir, siempre, del uso ordinario del 'diagnóstico' como un acto de habla; es decir, enfatizar que, antes de constituir una cuestión estrictamente epistémica u ontológica, diagnosticar equivale a establecer una promesa entre dos seres humanos de carne y hueso 9 . Quizás, incluso, convendría ahora ir un poco más lejos y poner en tela de juicio nuestro objeto mismo de reflexión. Surge entonces la pregunta: ¿por qué es necesario diagnosticar? Por ejemplo, es muy interesante el hecho de que Bentall, uno de nuestros interlocutores principales, sugiera abandonar del todo dicha categoría:

La clave está en reconocer que, mientras que no podemos ponernos de acuerdo acerca de quién tiene 'esquizofrenia' y quién tiene 'desorden bipolar', [sí] podemos estar de acuerdo en quién experimenta alucinaciones auditivas, quién experimenta delusiones paranoicas, quién es hipomaníaco, etcétera. En efecto, salvo que hayan sido educados para ello por profesionales de la salud bienintencionados, los pacientes que llegan a la clínica psiquiátrica nunca se quejan de 'esquizofrenia' o de 'desorden bipolar', sino de varios tipos de comportamientos y experiencias que los doctores llaman 'síntomas', pero que sería mejor llamar 'quejas' ['complaints'. Cuando intentamos entender los mecanismos que subyacen a las quejas, no tenemos que preocuparnos acerca de si la persona que, por ejemplo, escucha voces es diagnosticada como padeciendo de 'esquizofrenia' o de 'desorden bipolar', y el problema de la clasificación puede, por ende, ser ignorado en su conjunto de manera segura. Una vez que las quejas sean explicadas, ya no habrá 'esquizofrenia' ni 'desorden bipolar' detrás para explicar luego (p. 166).

No habría, pues, una esencia de la 'enfermedad mental' más allá de todas las quejas de los pacientes o, en general, de los afectados ${ }^{10}$. Como bien se

9 Sobre el problema del conocimiento, Austin es sumamente esclarecedor al sentenciar que no se trata, como bien se ha dicho, de un asunto en torno a las condiciones universales y necesarias para determinar la verdad y la justificación de un conjunto de creencias; por el contrario, "cuando digo'yo sé' [l know], le doy a otros mi palabra, le doy a otros mi autoridad para decir que 'S es P'"' (Austin 1961, 67). En tanto acto de habla, el conocimiento y, en este caso particular, el diagnóstico son ante todo ilocuciones compromisorias, equiparables en gran medida al acto de prometer.

10 Valdría la pena volver a enfatizar el componente social de las quejas, ya que, como bien ha sugerido Canguilhem, dicho anclaje ético habría de revelarse no solo en ciertos casos de psicopatología, sino también de fisiopatología. En particular, el episodio Designer DNA de la serie documental Explained (2018) es sumamente ilustrativo a este respecto: muchas personas 
ha dicho, es curioso que Wittgenstein ofrezca un argumento similar a propósito de los juegos del lenguaje: si uno remueve, uno por uno, todos los usos de una palabra, no quedará al final ninguna 'esencia' que constituya el significado. Análogamente, Rahel Jaeggi no duda en afirmar lo mismo incluso acerca de las personas y de sus identidades: siguiendo la máxima nietzscheana de que "no hay un ser detrás del hacer", Jaeggi afirma que, como bien he indicado a este respecto en una reseña, "ser uno mismo no equivale a remontarse románticamente a una dimensión interior de autonomía prístina, sino a establecer una relación fluida, múltiple y apropiativa respecto del mundo [social]" (Maruy 2019, 108).

¿Es preciso entonces descartar de una vez por todas la noción de diagnóstico? Como el lector habrá podido intuir, la cuestión no es tan sencilla y amerita, cuanto menos, una reflexión final. Cuando Bentall critica la noción de diagnóstico y sugiere, en cambio, optar por un modelo de 'quejas', está sin duda pensando solamente en la concepción judicativa y, a fortiori, paternalista del diagnóstico. Por lo tanto, ¿no valdría la pena considerar también las implicancias éticas de la concepción compromisoria que hemos propuesto $y$, en tal sentido, explorar hasta qué punto sería, o no, conveniente apostar por preservarla? Acaso una primera pista en esta dirección haya sido formulada ya por Miranda Fricker: como bien se ha

dentro de la comunidad de sordos dirían que no 'padecen' propiamente de una 'enfermedad'; asimismo, se encuentra el testimonio de una madre que 'padece' de enanismo: "La idea de que todos estamos enfermos, de que sufrimos, de que sufro de enanismo... No, he vivido con enanismo durante 39 años. Estoy orgullosa de ser una segunda generación criando a una tercera generación de personas que viven con enanismo. Yo no sufro de [enanismo]... sufro por la manera que la sociedad me trata". Así pues, si una definición esencial de la enfermedad es controversial incluso en fisiopatología, donde los fundamentos biológicos de las anomalías son claros, el problema deviene mucho más complicado para la psicopatología. No es fortuito entonces que Thomas Szasz postule lo siguiente: la enfermedad mental es un concepto primordialmente ético y no científico en la medida en que, desde el punto de vista psiquiátrico y por implicación psicológico, no expresa una fisiopatología cerebral en sentido estricto, puesto que tal objeto de estudio correspondería más bien a la neurología; en cambio, se enfatiza que "la noción de síntoma mental [queja, en este caso] está inextricablemente ligada al contexto social y particularmente ético en el cual ocurre, así como la noción de síntoma corporal está ligada a un contexto genético y anatómico" (Szasz 1991, 14). En otras palabras, una psicopatología solo deviene inteligible en el seno de las relaciones humanas: es por ello que Szasz insiste en que "cuando uno habla de enfermedad mental, la norma respecto de la cual se mide una desviación es un criterio psicosocial y ético" (Szasz 1991, 15). Entonces, no es que haya una 'enfermedad mental' que se exprese en quejas sociales, sino que las quejas sociales mismas son la presunta 'enfermedad mental'. 
sugerido a propósito del concepto de injusticia hermenéutica que la autora acuña, este fenómeno "ocurre en un nivel básico cuando una brecha en los recursos interpretativos colectivos pone a alguien en una desventaja injusta en lo que se refiere a hacer sentido de sus experiencias sociales (...) [por ejemplo, cuando] uno sufre de acoso sexual en una cultura que aún carece de dicho concepto crítico" (Fricker 2007, 1). Nombrar, en este tipo de casos, puede adquirir una importancia terapéutica, social y política, ya que permite que ciertos malestares individuales sean articulados públicamente y puedan, por lo mismo, convertirse en objeto de comunicación, de escrutinio, de debate, de crítica e incluso de tipificación jurídica. Piénsese, por ejemplo, en el surgimiento de nociones relativamente nuevas como bullying, estrés postraumático, discriminación, depresión postparto, violación dentro del matrimonio, etcétera, cuya ausencia epistémica impedía visibilizar y comprender socialmente las dimensiones éticas de aquellos cúmulos de malestar.

Desde este enfoque, el diagnóstico no sería considerado como una imposición determinante por parte de la autoridad del psiquiatra, sino como la posibilidad de construir conjuntamente, a partir del vínculo compromisorio y reflexionante entre el terapeuta y el paciente, un concepto que permita hacer expresable, comprensible, identificable e inteligible el cúmulo de malestares en cuestión. Un aspecto sugerente de esta propuesta es que habría de partir no de un modelo biológico y hereditario de la 'enfermedad mental', sino desde una tematización social de los motivos que pueden encontrarse en el origen de las 'quejas' del paciente. De nuevo, en palabras de Bentall:

Al concentrarse en síntomas antes que en diagnósticos, podemos ver cómo las experiencias de los pacientes surgen de manera comprensible de sus infortunios. Lejos de asumir que un funcionamiento anormal del cerebro es la causa primaria de la enfermedad [illness], la investigación orientada a las quejas muestra que el cerebro con problemas [the troubled brain] no puede ser considerado en aislamiento del universo social. Clínicamente, esto nos lleva a reconocer que las historias que los pacientes nos cuentan son importantes, y que hay una línea divisoria muy delgada entre 'ellos' que están enfermos [ill] y'nosotros' que estamos cuerdos [sane] (Bentall 2010, 182). 
Ahora bien, la idea de pensar constructivamente en un diagnóstico como instancia pública y comprensible que articule, a partir de narrativas reflexionantes, malestares difusos y diversos: dicha idea permitiría denunciar y, en última instancia, transformar desde el lazo compromisorio entre terapeuta y paciente las condiciones sociales e institucionales que han fomentado, en primer lugar, el surgimiento de tales 'síntomas'. En este sentido, el establecimiento cooperativo de este tipo de diagnósticos se encontraría ligado de manera intrínseca al desarrollo de relaciones de reconocimiento recíproco entre terapeutas y pacientes. Por ende, el diagnóstico compromisorio serviría también como un medio de crítica social, el cual habría de oponerse, quizás heroica o por lo menos necesariamente, a la tendencia contemporánea de privatizar malestares que, en realidad, se derivan de arreglos, prácticas y convenciones sociales injustas ${ }^{11}$.

Caso contrario, la imposibilidad de resignificar el sentido del acto de habla de diagnosticar hacia un ejercicio hermenéutico abierto donde los agentes involucrados puedan convenir y tematizar de manera conjunta, recíproca y libre los orígenes sociales de aquellos problemas que aquejan al paciente: dicha imposibilidad fáctica revelaría hasta qué punto los procesos de normalización y de sedimentación de valores en nuestros actos de habla se han vuelto, o no, tiránicos. Es decir, hasta qué punto vivimos, o no, en una tiranía sutil, donde los profesionales de la salud mental se restringen a un dispositivo de control sumamente legítimo que estigmatiza cualquier comportamiento fuera de las normas dadas, que privatiza cualquier reacción de padecimiento ante injusticias sociales y, en cambio, fomenta la adaptabilidad mecánica de las personas a las exigencias, a veces crueles

11 A propósito de este tema, es indispensable tomar en cuenta la siguiente constatación histórica de Axel Honneth sobre la esfera laboral contemporánea, según quien, "para la mayoría de asalariados, en los últimos veinte años las oportunidades de saberse integrado como un par entre pares en el contexto de cooperación del mercado capitalista se han reducido en vez de haber aumentado" (Honneth 2014, 330-331). Asimismo, quizás lo más problemático de este escenario sea que dichas injusticias no suscitan ya respuestas colectivas de rechazo o indignación; en cambio, predomina la privatización patológica del descontento, la enajenación comunicativa, la individualización de la atribución de responsabilidades y, en suma, la disolución de un "nosotros" que comprenda al mercado como un organismo social de reciprocidad no coercitiva (Honneth, 2014, 332-335). Ante dichos pincelazos lúgubres sobre la realidad laboral y la injusticia testimonial imperante, ¿no sería entonces la propuesta de un diagnóstico compromisorio una tentativa por ir 'en busca del reconocimiento perdido'? 
o indiferentes, que imponga el entorno ${ }^{12}$. En todo caso, el lenguaje se ha mostrado una vez más como una instancia crítica para repensar nuestras formas de relacionarnos con las personas vulnerables, nuestras formas de comprender o de juzgar el malestar ajeno, de tratarlo, de ignorarlo, silenciarlo, medicalizarlo o de escuchar, atentos, las historias que yacen detrás: repensar, en suma, nuestras formas de vida y, en este caso concreto, nuestros compromisos éticos y nuestras responsabilidades sociales al momento de decir'lo normal'.

\section{Bibliografía}

American Psychiatric Association, 2013. Diagnostic and statistical manual of mental disorders (5th ed.). Arlington, VA: Author.

Arendt, Hannah, 1977. The Life of the Mind. Orlando: Harcourt.

Austin, John, 1961. Philosophical Papers. Oxford: Oxford University Press.

Austin, John, 1975. How to Do Things with Words. Harvard: Harvard Education Press.

Bauer, Nancy, 2015. How to Do Things with Pornography. Cambridge: Harvard University Press.

Bentall, Richard, 2010. Doctoring the Mind: Why Psychiatric Treatments Fail. London: Penguin Books.

Berman, J. (producer), Helpert, J. (director), 2019. Io. United States: Mandalay Pictures.

Canguilhem, Georges, 1965/2015. La connaissance de la vie. Paris: Vrin.

Canguilhem, Georges, 1966/2015. Le normal et le pathologique. Paris: Presses Universitaires de France.

Canguilhem, Georges, 1998. ¿Qué es la psicología? Traducción de A. Sampson, Revista Colombiana de Psicología, 7, 7-14.

Cavell, Stanley, 1979. The Claim of Reason: Wittgenstein, Skepticism, Morality and Tragedy. Oxford: Oxford University Press.

12 Tal es, de hecho, la concepción 'liberal' de la psicología que Canguilhem critica: el psicólogo como una herramienta que facilite la adaptabilidad de los pacientes a las exigencias, sobre todo económicas, del medio (Canguilhem 1998, 12-14). Para un abordaje político de este problema desde un análisis genealógico del neoliberalismo, cf. la reciente obra de Barbara 
Constantinidès, Yannis, 2000. Nietzsche législateur - Grande politique et réforme du monde. En: Lectures de Nietzsche. J.F. Balaudé \& P. Wotling (eds.). Paris: Librairie Nationale Française.

Delgado, Honorio, 1953. Curso de psiquiatría. Lima: Fondo Editorial de la Universidad Cayetano Heredia.

Demazeux, Steeves, 2015. The Ideal of Scientific Progress and the DSM. The DSM-5 in Perspective: Philosophical Reflections on the Psychiatric Babel. Dordrecht: Springer.

Felman, Shoshana, 2003. The Scandal of the Speaking Body. Stanford: Stanford University Press.

Foucault, Michel, 1961. Histoire de la folie à l'âge classique. Paris: Gallimard.

Foucault, Michel, 2015. La naissance de la clinique. En: Fuvres I. Paris: Gallimard.

Fricker, Miranda, 2007. Epistemic Injustice: Power \& the Ethics of Knowing. Oxford: Oxford University Press.

Honneth, Axel, 2014. El derecho de la libertad: Esbozo de una eticidad democrática. Buenos Aires: Katz Editores.

Jaeggi, Rahel, 2004/2014. Alienation Traducción de F. Neuhouser y A. E. Smith. New York: Columbia University Press.

Joas, Hans, (2006). Wie entstehen Werte? Conferencia presentada en Gute Werte, schlechte Werte. Gesellschaftliche Ethik und die Rolle der Medien, 15 de setiembre del 2006. Freiwillige Selbstkontrolle Fernsehen: https://fsf.de/data/ hefte/pdf/Veranstaltungen/tv_impuls/2006_Ethik/Vortrag_Joas_authorisiert_061017.pdf. Consultado 16 octubre 2019.

Kant, Immanuel, 1790/1986. Kritik der Urteilskraft. Ditzingen: Reclam.

Kant, Immanuel, 1790/1985. Critique de la faculté de jugar. Paris: Gallimard.

Klein, E., Rozansky, K., Gordon, C., Mumm, Ch., Nishimura, L., Posner, J., SpingarnKoff, J. \& Townsend, K. (productores), 2018. Explained [documental]. Estados Unidos: Netflix.

Lara, María Pía, 2009. Narrar el mal: una teoría posmetafísica del juicio reflexionante. Barcelona: Editorial Gedisa.

MacIntyre, Alasdair, 1981/2007. After Virtue. Indiana, United States of America: University of Notre Dame Press.

Maruy, Rodrigo, 2019. Reseña: Alienation, Metanoia, 3, 103-109.

Medina, José, 2017. Varieties of Hermeneutical Injustice. En The Routledge handbook of epistemic injustice [ed. Kidd, I. J., Medina, J., Pohlhaus, G. Jr]. New York: Routledge.

Stiegler, Barbara, 2019. « Il faut s'adapter » : Sur un nouvel impératif politique. Paris : Gallimard. 
Szasz, Thomas, 1991. Ideology and Insanity: Essays on the Psychiatric Dehumanization of Man. New York: Syracuse University Press.

Wittgenstein, Ludwig, 1953/2002. Investigaciones Filosóficas. Barcelona: Editorial Crítica

Zaentz, S. y Douglas, M. (producers), Forman, M. (director), 1975. One Flew Over the Cuckoo's Nest. United States: Fantasy Films. 